\title{
Sustainable medicines use in clinical practice - a clinical pharmacological view on ecopharmacostewardship
}

\author{
Elizabeth Adeyeye ${ }^{1}$, Benjamin New ${ }^{2}$, Fangyue Chen $^{3}$, Spoorthy Kulkarni ${ }^{4}$, Marie Fisk \\ (Associate Senior Editor) $^{4}$, and Jamie Coleman ${ }^{5}$ \\ ${ }^{1}$ Barts Health NHS Trust \\ ${ }^{2}$ Ninewells Hospital and Medical School \\ ${ }^{3}$ University College London Hospitals NHS Foundation Trust \\ ${ }^{4}$ University of Cambridge \\ ${ }^{5}$ University Hospitals Birmingham NHS Foundation Trust
}

September 25, 2021

\begin{abstract}
Climate change continues to pose a dangerous threat to human health. However, not only is health impacted by this crisis, healthcare itself adds to the problem, through significant contributions to green house gas emissions. In the UK, the National Health Service (NHS) is responsible for an estimated $4 \%$ of the overall national carbon footprint. Medicines account for a quarter of this and whilst they are vital in in health now, through sustainable use they can also positively influence the environmental health of the future. In this review, we explore how clinical pharmacologists and other health care professionals can practice sustainable medicines use or eco-pharmaco-stewardship. We will discuss current and near future environmental practices within the NHS, which we suspect will resonate with other health systems. We will suggest approaches for championing eco-pharmaco-stewardship in drug manufacturing, clinical practices and patient use, to achieve a more a sustainable healthcare system.
\end{abstract}

\section{Hosted file}

Sustainable medicines use in clinical practice - a clinical pharmacological view on eco-pharmaco-stewar available at https://authorea.com/users/436977/articles/538936-sustainable-medicines-use-inclinical-practice-a-clinical-pharmacological-view-on-ecopharmacostewardship 